\title{
Neuropsychological Deficits in Adolescents with Fetal Alcohol Syndrome: Clinical Findings
}

\author{
Heather Carmichael Olson, Julie J. Feldman, Ann P. Streissguth, \\ Paul D. Sampson, and Fred L. Bookstein
}

\begin{abstract}
Understanding the nature of cognitive deficits among adolescent patients with fetal alcohol syndrome (FAS) can direct future research on assessment and intervention. In an exploratory study, nine nonretarded teenagers with FAS were administered tests of 10 and adaptive behavior, and neuropsychological tests presumed sensitive to alcohol effects. Their performance was compared with psychometric norms and to data from a sample of 174 adolescents with minimal or no prenatal alcohol exposure. These nonretarded FAS patients commonly showed behavior problems, decreased social competence, and poor school performance. Neuropsychological testing revealed significant deficits, although no one neuropsychological profile characterized all patients and not all tests revealed problems. Relatively intact performance was observed in procedural memory, some measures of reaction time, and some reading measures. Deficits were seen on attentional and memory tasks tapping visual-spatial skills, short-term auditory attention and memory, declarative learning, and cognitive flexibility and planning. Difficulties in processing speed and accuracy were also seen. Comparison with a subgroup of $\mathbf{5 2}$ nonalcohol-exposed or minimally alcohol-exposed adolescents with a similar range of 10 scores demonstrated that deficits among these FAS patients were not fully explained by a general lowering of $I Q$.
\end{abstract}

Key Words: Fetal Alcohol Syndrome (FAS), Adolescence, Cognition, Neuropsychology, Maternal Alcoholism.

$\mathbf{F}$ ETAL ALCOHOL syndrome (FAS) is a serious developmental disability caused by the teratogenic effects of prenatal alcohol exposure on the growing fetus. FAS is defined by a characteristic pattern of prenatal and/or postnatal growth deficiency, specific craniofacial malformations, and variable central nervous system (CNS) dysfunction. ${ }^{1-4}$ Follow-up studies, at first primarily focused on retarded patients and later on the broader range of individuals with FAS, have documented the long-term nature of their CNS dysfunction and their ongoing cognitive and behavioral problems. These studies have typically reported on general parameters of adaptive behavior, achievement,

From the School of Medicine, Department of Psychiaty and Behavioral Sciences (H.C.O., A.P.S.), and College of Arts and Sciences, Department of Statistics (P.D.S.), University of Washington, Seattle, Washington; College of Social and Behavioral Sciences, Department of Psychology (J.J.F.), University of Arizona, Tucson, Arizona; and the Institute of Gerontology (F.L.B.), University of Michigan, Ann Arbor, Michigan.

Received for publication February 6, 1996; accepted September 8, 1998

This work was partially supported by Grant R01 AA01455-14-17 to A.P.S.) from the National Institute on Alcohol Abuse and Alcoholism.

Reprint requests: Heather Carmichael Olson, Ph.D., FAS Diagnostic and Prevention Network and Fetal Alcohol and Dnig Unit, Box 359112, University of Washington, Seattle, WA 98195.

Copyright (O) 1998 by The Research Society on Alcoholism. and IQ. ${ }^{5-12}$ But clinicians working with the full spectrum of individuals with FAS are often struck by their patients' varied and lasting cognitive deficits-seen even among higher functioning patients with relatively unaffected overall performance on IQ tests, who may not be eligible for educational or social services. These more specific cognitive deficits are especially notable as individuals with FAS reach adolescence, and often do less well in day-to-day function than would be expected based on earlier intellectual test performance. ${ }^{8}$ Indeed, these cognitive deficits may partially underlie the mental health problems and other real-life "secondary disabilities" found with striking frequency among individuals with FAS. ${ }^{1-13}$ Thus, it is essential to explore and identify the functional deficiencies and preserved abilities of fetal alcohol-affected individuals, particularly as they approach adulthood ${ }^{14}$ to more fully understand their developmental course and prognosis, and to create appropriate supports and intervention strategies.

A small but growing number of neuropsychological studies have recently provided more specific descriptions of the patterns of performance among individuals with FAS. Some studies involve younger subjects. ${ }^{15-20}$ Data on older, usually retarded, patients are available in pioneering case reports of neuropsychological test performance paired with brain imaging studies. ${ }^{21,22}$ To date, only a limited number of studies have examined older, nonretarded, higher functioning individuals with FAS. These small sample studies usually focus on alcohol-affected subjects drawn from a wide age range. They sometimes include not only subjects diagnosed with FAS, but also those who show some of the features of FAS but do not meet criteria for the full syndrome [for whom the label of fetal alcohol effect (FAE) has traditionally been applied]. When comparison subjects are included in these studies, information on their in utero alcohol exposure has typically been gathered retrospectively or is not known.

In a pilot investigation, Kerns, Don, and colleagues compared the performance of 16 nonretarded adolescents and adults with FAS (aged 16 to 27) to norms on a broad battery of standard neuropsychological tasks. FAS patients had difficulties in aspects of verbal learning and memory, complex sustained and alternating auditory attention (and attention under distraction conditions), and executive function (including many perseveration errors). Patients with borderline IQ demonstrated greater levels of impairment, but even for those with average IQ the number and range 
of cognitive deficits seen were considered to be more than would be predicted based on IQ alone. ${ }^{23}$

Kodituwakku and colleagues ${ }^{24}$ focused on the role of attention in the control of action and especially on the important cognitive function of flexibly guiding behavior by plans or mental representation. With 9- to 18-year-old subjects, they compared a mixed sample of 10 higher functioning patients with FAS or FAE versus controls with no known prenatal alcohol exposure who were matched for age and level of receptive vocabulary. No group differences were found on measures of verbal knowledge or the ability to acquire and retain visual or verbal materials, or on several self-regulatory tasks that demanded continuous upgrading of working memory and inhibiting dominant responses. Alcohol-affected subjects did show specific difficulties on five tasks assessing auditory attentional capacity, planning, fluid intelligence, and feedback utilization (or maintaining and shifting response sets). Kodituwakku and coworkers $^{25}$ suggested that their findings revealed selective impairment among alcohol-affected individuals in the ability to flexibly manage certain goals in working memory, an important area of deficit since aspects of working memory may play an essential role in higher order problem-solving. Kopera-Frye et al. compared 29 older (aged 12 to 44 ), higher functioning patients who had a clear diagnosis of FAS to controls matched for age, sex, and educational level (although with no information given on IQ or prenatal exposures). They also found intact performance on basic verbal tasks and greatest difficulty on a task sensitive to frontal systems dysfunction: cognitive estimation. ${ }^{26}$

Mattson and coworkers scrutinized verbal learning and memory in a group of 20 FAS patients ranging widely in age from 5 to 16 years. Patient performance was compared with both age-, sex-, and ethnicity-matched controls and a mental age-, sex-, and ethnicity matched control group. No data on prenatal alcohol exposure among controls was reported. Compared with age-matched controls, individuals with FAS exhibited deficits on measures of verbal learning, and memory had more perseverative errors and false positive responses, but showed normal rates of forgetting after a delay. Many, but not all, deficits appeared related to lowered intellectual function. More specifically, alcoholrelated deficits were attributed to the encoding rather than retrieval level of memory and were seen as consistent with a response inhibition deficit. ${ }^{27}$ In additional neuropsychological investigations of patients in a similar age range, Mattson and colleagues identified deficits (relative to controls) among a mixed sample of alcohol-affected patients in visual processing of "local" (detail) features rather than "global" (configural) information, ${ }^{28}$ and on measures of word comprehension, naming ability, academic skills, visual-motor integration, nonverbal learning, and fine motor speed and coordination. ${ }^{29} \mathrm{~A}$ reduction in IQ alone was not generally sufficient to fully account for these specific deficits.

A recent review of neuropsychological studies summa- rized the wide variety of neurobehavioral deficits among individuals with FAS. In this review, Mattson and Riley ${ }^{30}$ highlighted the need for more thorough study of problemsolving and complex visuospatial skills, and more specific evaluation of the components of attention. The present exploratory study provides information in these understudied areas and further explores memory, adding to the emerging literature on long-term CNS dysfunction among individuals with FAS. Tightly focused on the period of adolescence and the full fetal alcohol syndrome, this study explores the skills of patients who are higher functioning (using Full-Scale IQ as a commonly accepted indicator of function). Patterns of group performance and individual differences are examined in a group of nine patients, all teenagers between 14 and 16 years who have a clear diagnosis of FAS. Using a wide-ranging battery designed to be sensitive to alcohol effects, the cognitive and behavioral status of this heavily alcohol-exposed, relatively homogeneous patient group is compared with epidemiological data from a group of adolescent peers involved in a prospective longitudinal study who were, according to maternal report during pregnancy, not exposed or only minimally exposed to alcohol in utero. The IQ comparison subgroup of teens from this prospective study is included to investigate whether the FAS patients' neuropsychological deficits can be explained by a general lowering of intellectual function.

\section{METHODS}

Subjects

The FAS patient group included all adolescents (aged 14 to 16) of borderline and average IQ drawn from the research patient list of the Fetal Aicohol Follow-up Study at the time of this study, who were available for laboratory testing during the study period. All subjects recruited agreed to participate. This clinical sample included nine teenagers with the full FAS as diagnosed by a dysmorphologist trained in recognizing FAEs. All patients had been exposed to high levels of maternal alcohol use during pregnancy, spoke English, and had no major sensory handicaps. Six adolescents had WISC-R Full-Scale IQ scores ${ }^{31}$ within the low-to-high average range (from 80 to 119 ) and three within the borderline range (from 70 to 79). Three patients with FAS were male. One patient was Native American, one was black, and the others were white.

At the time of testing, one FAS patient lived in a foster family, and three patients lived with a birth parent (two of whom had remarried). The remaining five were in adoptive situations, and none had been raised on a reservation. One birth family was of lower socioeconomic status, and all other study families could be considered middle class. Two patients had consistently lived in stable birth homes, whereas on average, the remaining patients had spent 11 years in their longest stable home placement. Those leaving birth families, usually because of abuse or neglect related to matemal alcohol abuse, had an average of four home placements. Typically patients entered their adoptive home at age 3 or 4 , experiencing environmental disruption early in life and then settling into a stable home. However, one patient was not adopted until 12 years of age, and another had recently moved into a foster home (but saw his adoptive parents regularly).

Test scores of this nonretarded, heavily aicohol-exposed FAS patient group were compared with data from subsets of 14- to 15-year-olds drawn from the Seattle Longitudinal Prospective Study on Alcohol and Pregnancy (the "Cohort Study"). ${ }^{32}$ To examine alcohol effects on neuropsychological outcomes, a comparison group was selected to include the 174 
Table 1. Neuropsychological Measures

\begin{tabular}{|c|c|c|c|}
\hline Task & Constructs measured & Dependent variables & Key reference \\
\hline Continuous Performance Task (CPT) & $\begin{array}{l}\text { Sustained attention ["Sustaining } \\
\text { component"]" }\end{array}$ & $\begin{array}{l}\text { No. of errors (omission and commission); } \\
\text { RT; standard deviation of RT } \\
\text { (For "X", "AX", "Degraded X" Task } \\
\text { conditions) }\end{array}$ & Rosvold et al. $(1956)^{38}$ \\
\hline Letter Cancellation Task (LCT) & $\begin{array}{l}\text { Perceptual-motor speed and attention } \\
\text { ["Focusing component"]" }\end{array}$ & $\begin{array}{l}\text { Total no. of letters crossed out; no. } \\
\text { correct; no. of errors (omission and } \\
\text { commission) } \\
\text { (For "Capitals," "Spaces," and "Both" } \\
\text { conditions) }\end{array}$ & Talland $(1965)^{40}$ \\
\hline Wisconsin Card Sorting Test (WCST) & $\begin{array}{l}\text { Concept identification; cognitive flexibility; } \\
\text { attention ["Shifting set component"] }\end{array}$ & $\begin{array}{l}\text { No. of categories; \% of "other" } \\
\text { responses; \% of card-sorting errors }\end{array}$ & Heaton $(1981)^{41}$ \\
\hline $\begin{array}{l}\text { Digit Span Subtest (DS) (from WISC- } \\
\text { R) } \dagger\end{array}$ & $\begin{array}{l}\text { Short-term memory for spoken digits; } \\
\text { working memory; ["Encoding } \\
\text { component"] }\end{array}$ & $\begin{array}{l}\text { Raw scores (no. correct) for Digits- } \\
\text { Forward and Digits-Backward }\end{array}$ & Wechsier $(1974)^{3 t}$ \\
\hline Seashore Rhythm Test $\ddagger$ & $\begin{array}{l}\text { Short-term memory for tone patterns; } \\
\text { auditory attention }\end{array}$ & No. of errors & Seashore et al. $(1960)^{44}$ \\
\hline Sequence Learning Task (SLT) & $\begin{array}{l}\text { Procedural and declarative memory; } \\
\text { response time }\end{array}$ & $\begin{array}{l}\text { Procedural score; Declarative score; } \\
\text { block } 1 \text { RT }\end{array}$ & $\begin{array}{l}\text { Nissen \& Bullemer } \\
\qquad(1987)^{46}\end{array}$ \\
\hline Spatial-Visual Reasoning Task (SVRT) & Visual-spatial reasoning and memory & No. correct; median study time & Hunt et al. $(1987)^{48}$ \\
\hline Stepping Stone Maze Test (SSM) & $\begin{array}{l}\text { Visual-spatial memory; ability to plan; } \\
\text { cognitive flexibility }\end{array}$ & $\begin{array}{l}\text { No. of trials to ist errorless run; no. of } \\
\text { trials to criterion }\end{array}$ & Milner $(1965)^{49}$ \\
\hline $\begin{array}{l}\text { Rapid Single Visual Presentation Task } \\
\text { (RSVP) }\end{array}$ & $\begin{array}{l}\text { Reading speed, memory, and } \\
\text { comprehension; verbal reasoning }\end{array}$ & No. correct; median reading speed & $\begin{array}{l}\text { Kintsch \& VanDijk } \\
\quad(1978)^{5-1}\end{array}$ \\
\hline $\begin{array}{l}\text { Word Attack Subtest (from } \\
\text { Woodcock Reading Mastery Tests) } \\
\text { (WA)§ }\end{array}$ & $\begin{array}{l}\text { Phonic and structural analysis; word } \\
\text { decoding skills }\end{array}$ & Raw score (no. correct) & Woodcock $(1987)^{52}$ \\
\hline
\end{tabular}

"These tasks comprise components of Mirsky et al.'s neuropsychological model of attention. ${ }^{39}$

$\dagger$ The DS and WCST are presumed tests of frontal lobe function. ${ }^{42.43}$

† The Seashore Rhythm Test is a task sensitive to right temporal lobe brain damage and depressed cerebral function. ${ }^{42}$

$\S$ Findings on the WA subtest show that reading-disabled individuais perform poorly on WA regardless of $I Q,{ }^{53}$ and $W A$ is a reading task not confounded by other dimensions of reading (such as guessing from content). ${ }^{54}$

adolescents who (according to maternal report) were either lightly or not exposed to alcohol in the prenatal period (the "Cohort comparison group"). To examine the relationship of IQ level to neuropsychological performance deficits, a smaller comparison group was sclected to include 52 of these 174 subjects who had IQ scores \pm 10 points of the mean IQ (91) of the FAS patient group (the "IQ comparison subgroup").*

\section{Measures}

Data were gathered from the FAS patients and Cohort Study subjects in a 4-hr laboratory session, which included research batteries of psychosocial measures and neuropsychological tasks. These batteries, originally assembled for the ongoing Cohort Study, are described in previous papers. $^{33-37}$

Neuropsychological Research Battery. The neuropsychological battery included attention, memory, and reading process tasks chosen to tap many cognitive skills thought to be affected by prenatal alcohol exposure, based on prior animal and human research. This battery-including a list of constructs assessed, dependent measures, and key references-is presented in Table 1. Tests in this table are listed in the order they appear in the "Methods" and "Results" sections of this paper.

Continuous Performance Task (CPT). The CPT ${ }^{38}$ is a visual vigilance task used to measure sustained attention and cognitive flexibility. ${ }^{39}$ Letters

* Note that all $I Q$ scores for the Cohort Study subjects were taken from the 7 year data collection time point, because IQ testing was not conducted in the Cohort Study at age 14. are flashed on a digital display screen. The subject is asked to respond by pressing a button whenever a particular target (the letter " $\mathrm{X}$ ") appears on the screen. There are three conditions of increasing difficulty: (1) subjects respond whenever an "X" appears on the screen ("X Task"), (2) subjects respond whenever an " $X$ " preceded by an " $A$ " appears on the screen ("AX Task"), and (3) subjects respond whenever an "X" appears, but all letters are visually degraded and consequently harder to perceive ("DX" or "Degraded X Task"). For each of the three CPT conditions, the dependent measures include number of errors of omission, number of errors of commission ("false alarms"), reaction time, and standard deviation of reaction time.

Letter Cancellation Test ( $L C T)$. The $\mathrm{LCT}^{40}$ is a paper-and-pencil measure of focused attention ${ }^{39}$ and perceptual-motor speed. In this timed task, the subject is given six paired sheets of typed letters, with the second sheet of each pair identical to the first. There are three conditions: The subject must cross out all (1) capital letters on the first two sheets ("Capitals" condition); (2) the letters before and after each double space on the second two sheets ("Spaces" condition); and (3) both capitals and letters indicating double spaces on the last two sheets ("Both" condition). For each LCT condition, the dependent variables include the total number of letters crossed out, number of correct responses, number of errors of omission, and number of errors of commission.

Wisconsin Card-Sorting Test (WCST). The WCST ${ }^{41}$ is a concept identification task and presumed neuropsychological test of frontal dysfunc$\operatorname{tion}^{42}$ that assesses the ability to abstract information and shift attentional set. ${ }^{39}$ It is a classic category-sorting test in which four criterion cards are presented that vary along three parameters: color, form (shape), and 
number of items. A computerized version of the WCST, developed in our laboratory, was used in this study. The subject is presented with a computer display of cards (one at a time) that vary along the same parameters, but is not told how to match the cards. Via a computer display of the words "correct" or "wrong," feedback is given to the subject about the accuracy of his/her choice after each sort. (Thus, there is never. any type of stated sorting "rule"). First, the subject is expected to sort according to the category of "color." After a criterion of 10 correct sorts has been met, the category is switched (without informing the subject) to "form," then to "number," and then this cycle is repeated. At times the subject may match cards according to one or more of the three parameters. At other times the subject may not appear to match according to any of the three parameters and is then said to make an "other" response. The WCST dependent variables are number of categories achieved (of a total of six), percentage of "other" responses (of total number of responses), and percentage of card-sorting errors (of total responses).

Digit Span (DS). The DS subtest from the WISC- $\mathrm{R}^{31}$ is presumed to measure short-term memory and auditory attention, and to be sensitive to frontal dysfunction. In this task, the subject listens to and repeats back digit strings that gradually increase in length. In the DS-Forward condition (DS-F), the subject repeats back the strings as they heard them. In the DS-Backward condition (DS-B) (which has been called a measure of executive function ${ }^{43}$ ), the subject repeats back the strings in reverse order. For DS, the dependent variables are the raw scores for DS-F and DS-B, indicating the length of strings successfully repeated in each condition.

Seashore Rhythm Test (SEASHORE). The Seashore Rhythm Test ${ }^{44}$ is a classic neuropsychological task thought to measure short-term memory and auditory attention, and found to be sensitive to right temporal lobe brain damage and depressed cerebral function. ${ }^{42}$ The subject's task is to listen to 10 pairs of patterned tone strings, and to decide whether each pair is the same or different. The dependent variable for SEASHORE is the total number of errors.

Sequence Learning Task (SLT). Squire ${ }^{45}$ describes two main systems involved in memory as procedural and declarative (i.e., knowing "how" and knowing "what"). In work with Korsakoff's syndrome and patients with Alzheimer's disease, Nissen and Bullemer ${ }^{46}$ used a sequence learning task to dissociate these two systems. The SLT task developed by Nissen was used in this study to assess procedural and declarative learning and memory. ${ }^{47}$ On each trial of the computer-administered SLT, an asterisk appears in one of four boxes, which are aligned on the screen above four keys on the keyboard. Subjects perform five blocks of 100 trials. During each trial, the subject presses the key matching the box in which the asterisk appears. During blocks 1 to 4 , the stimulus presentation follows a predictable 10-trial pattern. In block 5 , the stimuli are presented randomly. Reaction time on block 1 is defined as the median speed of response in pressing the key aligned with the asterisk during correct block 1 trials. Procedural learning of the sequence is operationally defined as the increase in reaction time (RT) from blocks 4 to 5 (the "Procedural Score"). The SLT was altered slightly to measure declarative learning. In a "Generate Task," subjects predict where the asterisk will appear next by pressing the corresponding key, which requires conscious remembering. The number of correct responses on the last 50 trials of the Generate Task is used as the "Declarative Score," because by the second 50 trials the subjects have had ample time to learn the sequence during the Generate Task itself. Dependent measures for the SLT task include the "Procedural Score," the "Declarative Score," and RT on block 1.

Spatial-Visual Reasoning Task (SVRT). The SVRT is a computeradministered task that measures visual-spatial reasoning, encoding and retrieval from working memory, and may tap skill in flexibly manipulating information. ${ }^{48}$ On each trial, two- to six-piece line drawing puzzle pieces are displayed on the computer screen. Some of the edges of the pieces are labeled with letters. The subjects' task is to imagine what composite shape the pieces would make when joined together along the labeled edges. Once subjects have mentally joined the puzzle pieces, they press the space bar and a single line drawing without edge markings appears. Given up to a 1-min study period (more than enough for most participants), subjects are asked to decide whether the shape is the same as the one they had imagined. Subjects complete four sets of 10 trials each. The dependent measures for SVRT include the total number of correct responses and the median study time overall for correct responses.

Stepping Stone Maze (SSM). The SSM, based on work by Milner, ${ }^{49}$ is presumed to be a test of visual-spatial memory-sensitive not only to disorders in spatial perception, but also to memory disorders in general..$^{50}$ It may also test cognitive flexibility and the ability to plan (and perhaps compromise of executive functioning). The computerized SSM developed in this lab requires the subject to find an "invisible" path through a practice $4 \times 3$ practice maze, and then an $8 \times 8$ "long maze." The long maze is a matrix of squares displayed on a computer screen that presents the subject with 19 choice points during the process of maze completion. To complete either maze, subjects must reach a criterion of three consecutive correct trials. Two dependent variables are used for the SSM: the number of trials needed to achieve the first errorless run on the long maze, and the total number of trials required to reach criterion on the long maze task.

Rapid Single Visual Presentation Task (RSVP). RSVP ${ }^{51}$ is a computeradministered task that measures reading speed, memory, and comprehension. Subjects read a simple story about four friends going on a hike. The story is presented one word at a time in the middle of the screen, with subjects controlling the rate of presentation by tapping the spacebar. After every few sentences, a set of three multiple choice questions is presented one at a time. There are three types of questions (anaphoric reference, memory, and inference), and a total of eight passages ( 24 questions). The dependent measures for RSVP include the number of correct responses to the questions and median reading speed (based on all of the words, except the first and last words of each sentence).

Word Attack (WA). The WA subtest ${ }^{52}$ is a phonological processing and reading decoding task. Reading-disabled individuals perform poorly on WA regardless of $I Q,{ }^{53}$ and WA is a reading task not confounded by other dimensions of reading (such as guessing from context). ${ }^{54}$ Subjects read out loud up to 45 novel strings of consonants and vowels, and are judged according to how their answers adhere to the grammatical rules of English. The dependent measure for WA is the raw score of number correct.

Intellectual, Achievement, Adaptive Behavior, and Behavior Problems Measures. Additional FAS patient data were available from recent records, including: The Wechsler Intelligence Scale for Children-Revised (WISC-R), ${ }^{31}$ the Wide-Range Achievement Test-Revised (WRAT-R), ${ }^{55}$ the Vineland Adaptive Behavior Scales (VABS), ${ }^{56}$ and the Child Behavior Checklist for 4- to 18-year olds (CBCL/4-18). ${ }^{57-59}$ The 14-year protocol for the Cohort Study subjects included the CBCL/4-18, but did not call for standardized IQ, achievement, or adaptive behavior assessment.

\section{Data Analysis}

In this exploratory study, medians (and median absolute deviations) were computed for the neuropsychological measures, because many of the variables were highly skewed. Interpretation of group differences on neuropsychological measures between the FAS patients and Cohort Study subjects was based primarily on inspection of plots of individual scores for the FAS patients with respect to a pair of boxplots depicting the distributions of the main Cohort comparison group $(n=174)$ and the smaller IQ comparison subgroup $(n=52)$. Wilcoxon two-sample rank-sum test statistics and $p$ values are also reported, although we encourage interpretation of these primarily as descriptive statistics for group differences. The small sample and exploratory nature of the current study limits the power of statistical tests, and the simultaneous consideration of a large number of outcomes makes it challenging to judge $p$ values for all the individual tests. The Wilcoxon rank-sum statistic and corresponding $p$ value (computed according to the usual statistical distribution theory and confirmed by a permutation distribution) is not designed to be sensitive to some of the demonstrated differences in outcome distributions between the FAS patients and comparison subjects from the Cohort Study. This is because the rank-sum statistic is most appropriate for identifying shifts in distribution, whereas the nine FAS patients deviate from the Cohort Study subjects according to a roughly bimodal distribution on some of the 


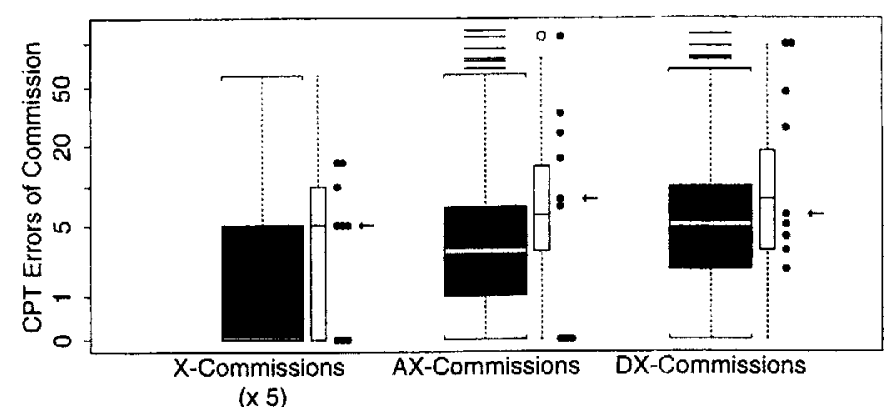

$(\times 5)$
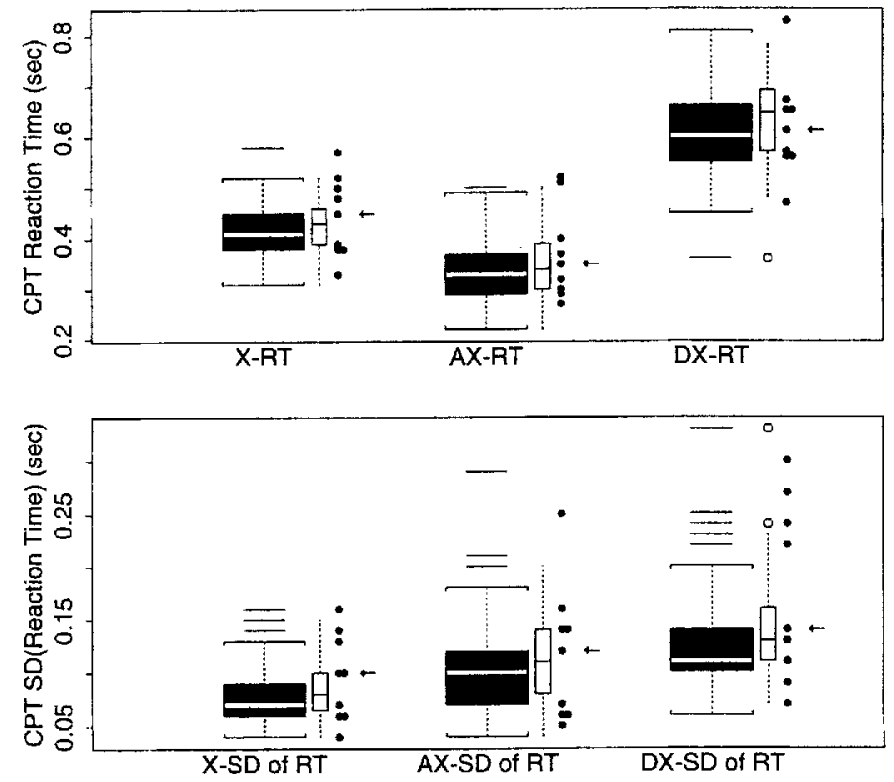

Fig. 1. Boxplots comparing performance of FAS patients and two comparison groups of Cohort Study subjects on the $X$ Task, AX Task, and Degraded $X$ Task of the Continuous Performance Test (CPT). The top panel compares the groups on the log-transformed number of commission errors in the three tasks. The middle panel compares the groups on RT (in seconds) in the three tasks. The bottom panel presents comparisons on the standard deviation of RT (in seconds) on the three tasks. On all CPT variables, higher scores indicate poorer performance.

outcome variables. For example: See CPT X-Commissions and AXCommissions and CPT X-SD of RT and AX-SD of RT in Fig. 1. On these variables, one-third to one-half of the FAS patients perform well, whereas the remaining patients perform poorly; conventional test statistics (including the Wilcoxon) would misleadingly indicate no differences at all. The rank-sum statistic, reported in the "Results" section as "w," has been scaled by its asymptotic standard error and, therefore, has an approximate standard normal distribution under the null hypothesis.

Figures 1 through 8 present the cognitive performance of the three groups on 31 neuropsychological variables that capture important aspects of their performance. $\dagger$ The column of single points at the right of each figure depicts scores of the nine FAS patients (individual data points falling on the same value have been placed so they can be distinguished in the plots). In each figure, the shaded boxplot on the left depicts the distribution of scores for the entire Cohort comparison group $(n=174)$ whereas the narrower, open boxplot in the middle portrays the score distribution for the IQ comparison subgroup (IQ range: $81-101, n=52$ ). An arrow marks the median of the nine FAS scores, for comparison with medians indicated by lines drawn in the middle of the two corresponding boxplots for the comparison groups. The limits of the boxes represent the upper and lower quartiles of the sample, whereas the height of the box is the interquartile range and covers $50 \%$ of the sample. Dashed lines on each boxplot extend to the most extreme observations (not more than a distance 1.5 times the interquartiles range from the nearest quartiles).
More extreme observations are represented by dashes for the shaded boxplot, and by small open circles for the open boxplot.

All figures display raw or log-transformed data. In the figures, the following variables are scaled so that higher numbers indicate better performance: the number of letters crossed out in the three LCT conditions; the WCST number of categories achieved; the DS raw scores on forward and backward conditions; the SLT procedural and declarative learning scores; the SVRT number correct and median study time; the number correct on RSVP; and the number of nonsense words read correctly on WA. All other variables are scaled so that higher numbers indicate poorer performance.

Intellectual, achievement, adaptive behavior, and behavior problems data for the FAS patients were summarized with means (and standard deviations), and compared with clinical cut-offs from existing psychometric norms. Descriptives for the CBCL/4-18, collected at the 14-year time point, are also presented for the Cohort Study subjects.

\section{RESULTS}

\section{Neuropsychological Findings}

Figures 1 through 8 show that the median of the FAS patient group falls approximately at or beyond the outer limit of the interquartile range of the reference Cohort comparison group distribution (indicating impairments) $61 \%$ (19 of 31 variables) of the time. Thus, the FAS patients (as a group) often perform poorly relative to the Cohort comparison group on tasks of attention, memory, cognitive flexibility, and one measure of reading accuracy. However, there is also wide variation within both groups on these measures. Differences are less marked between the FAS patients and the smaller IQ comparison subgroup, as might be expected because alcohol exposure is only one reason (among many) for lowered IQ. However, these comparisons do pinpoint certain aspects of attention and memory-and cognitive flexibility or planning-as areas affected to a greater magnitude among patients with FAS than among a group of peers comparable in level of IQ. This suggests that ascribing deficits to a general lowering of IQ does not fully capture the wide-ranging effects of prenatal alcohol exposure on cognition.

\section{Attention}

Sustained Attention. The three panels of Figure 1 display CPT commission errors, RT, and standard deviation of RT. On average (relative to the Cohort comparison group), the adolescent FAS patients tended toward lowered performance in the complex DX condition of the CPT, with difficulties seen in errors of commission $(w=-1.65, p=$ $0.098)$ and standard deviation of response time ( $w=-1.71$, $p=0.088$ ), but not in mean RT. There were no apparent differences between the FAS patient group and the IQ comparison subgroup. In this exploratory sample, not all individuals with FAS did poorly on this measure of sustained attention; typically, more than one-third of the teenagers with FAS performed at or above the mean of the Cohort comparison group.

Focused Attention. On average, patients with FAS had 

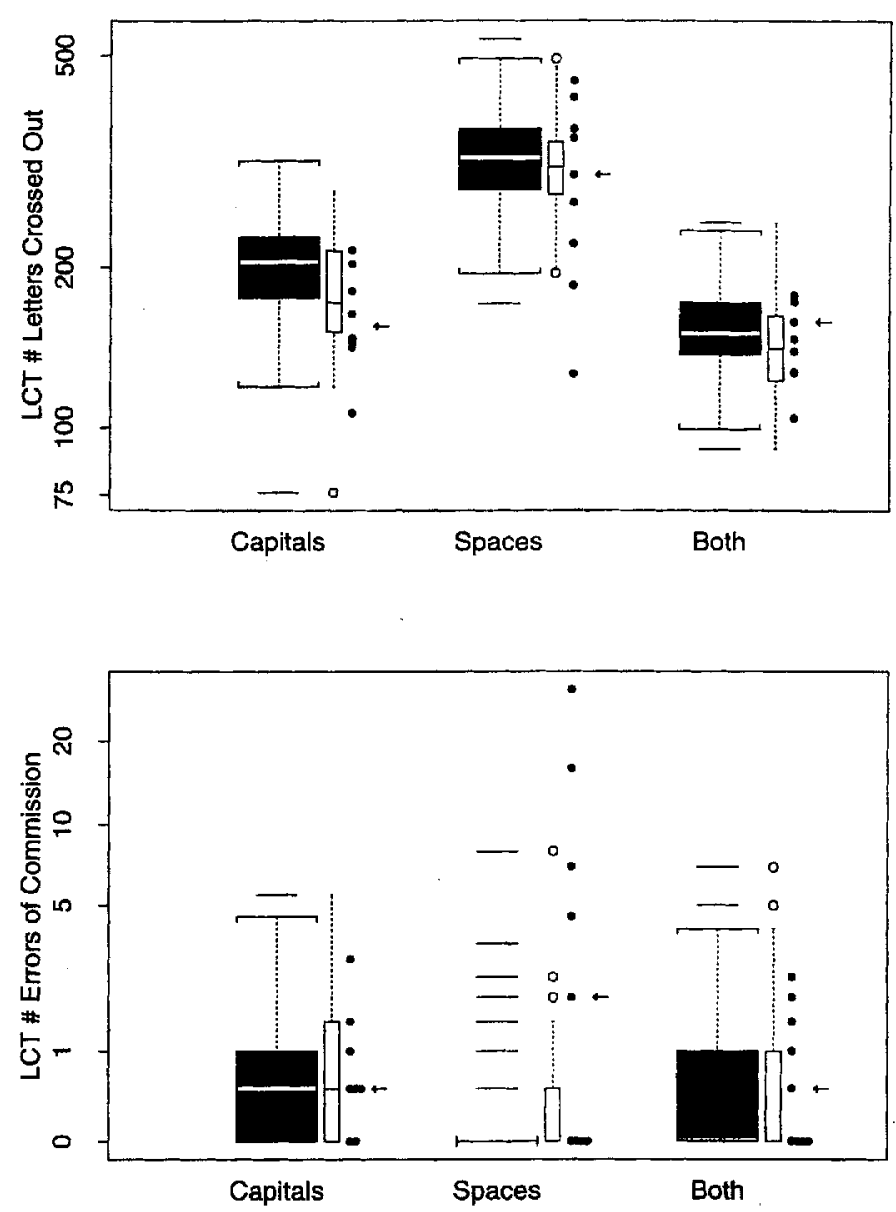

Fig. 2. Boxplots comparing performance of FAS patients and two comparison groups of Cohort Study subjects on the "Capital," "Spaces," and "Both" conditions of the LCT. The top panel compares groups on the number of letters crossed out in the three tasks, with higher scores indicating better performance. The bottom panel compares the groups on the number of commission errors in the three conditions, with lower scores indicating better performance. (Only 7 of 174 subjects in the Cohort comparison group subjects who completed the LCT made any errors on the "Spaces" condition).

more difficulty than the Cohort comparison group on aspects of the LCT (Fig. 2). These findings suggest specific decrements in focused attention, and in perceptual-motor or processing speed. FAS patients, on average, crossed out fewer total letters than the Cohort comparison group in the "Capitals" condition, perhaps acting more slowly when the task was new to them, but not in the subsequent "Spaces" and "Both" conditions. There were no apparent group differences across all three conditions in errors of omission and, as shown in Fig. 2, no differences in commission errors during the "Capitals" and "Both" conditions. Yet the FAS patients clearly made more commission errors in the "Spaces" condition, differing from both the Cohort comparison group $(w=-3.03, p=0.002)$ and smaller IQ comparison subgroup ( $w=-2.43, p=0.015$ ) who typically made no commission errors in this portion of the LCT. Clinical observations suggest problems among some FAS patients with response inhibition in the "Spaces" condition. This is the first LCT task requiring a switch to a new response rule, and a task in which subtle visual-spatial judgments and focused attention are essential.

Shifting Attentional Set. Mirsky and colleagues ${ }^{39}$ have suggested that the WCST measures the ability to shift attentional set, and the WCST is also thought to measure cognitive flexibility. As can be seen in Fig. 3, patients with FAS showed a higher percentage of WCST card-sorting errors $(w=-3.02, p=0.002)$, and thus completed far fewer WCST categories than did the cohort comparison group ( $w=2.93, p=0.003$ ), whereas also tending to make more non-rule-based ("other") error responses (suggesting disorganized, unplanned responses) $(w=-1.76, p=$ $0.077)$. The FAS patients, on average, also made more errors overall ( $w=-3.02, p=0.002)$ and completed fewer categories $(w=2.20, p=0.027)$ than did the IQ comparison subgroup. During performance on this computerized version of the WCST, which may be quite sensitive to impulsive or perseverative tendencies, FAS patients often made mistakes and responded with what appeared to be guesses or perseverations rather than considered answers. Because they typically achieved few categories, it was difficult to know how they adjusted their performance to a new rule; however, sorting according to "number" (the third category) often appeared to the examiners to be difficult for the adolescents with FAS.

\section{Memory}

Short-Term Memory. This sample of adolescents with FAS had somewhat greater difficulty than did the Cohort comparison group with short-term auditory memory (and auditory attention) as assessed via the DS subtest test (DS-F: $w=1.96, p=0.048$; DS-B: $w=1.97, p=0.048$ ), and the SEASHORE test $(w=-1.79, p=0.072)$ (Fig. 4). They also tended to do more poorly on the backwards condition of the DS subtest than did the smaller IQ comparison subgroup $(w=1.65, p=0.097)$.

Procedural and Declarative Memory. As shown in Fig. 5, patients with FAS did not differ from either comparison group on the SLT measure of procedural memory. Yet, on the measure of declarative memory, which requires conscious recall of learned information, the patients performed more poorly than did the larger Cohort comparison group $(w=2.55, p=0.011$ ) (but did not differ from the smaller IQ comparison subgroup). Similarly, FAS patients also tended to have a longer average response time on block 1 of the SLT than did the cohort comparison group ( $w=$ $-1.92, p=0.054$ ), suggesting slowed processing and motor response speed, given a demand for accuracy.

Visual-Spatial Memory. As a group, FAS patients had particular difficulties with spatial memory, reasoning, and cognitive flexibility as assessed by two neuropsychological tasks: the SVRT (Fig. 6) and the SSM (Fig. 7). Compared with the Cohort comparison group, they gave relatively few correct responses on the SVRT, performing close to chance level $(w=2.88, p=0.003)$, and tended to study the SVRT 

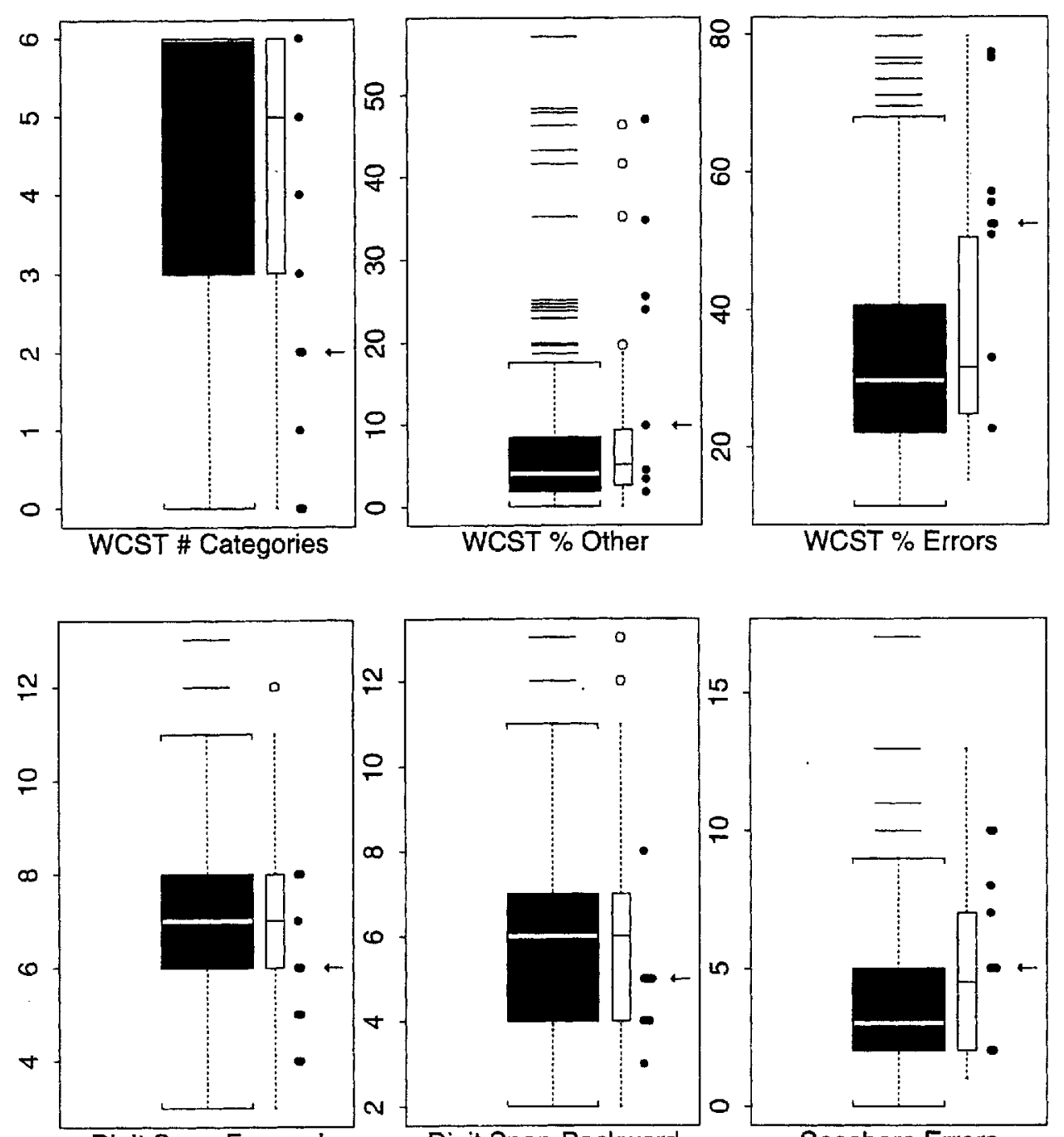

Digit Span-Forward

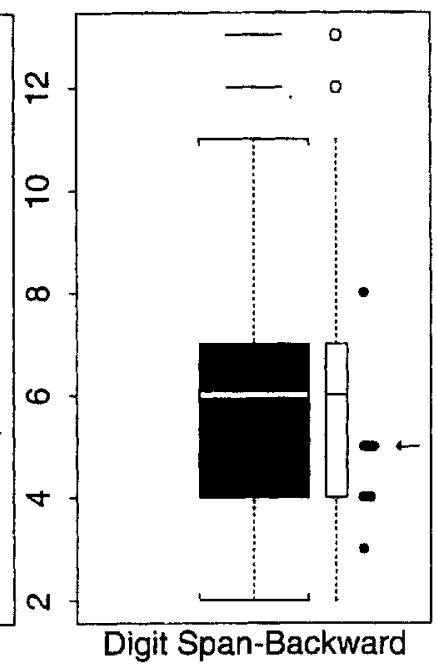

Digit Span-Backward

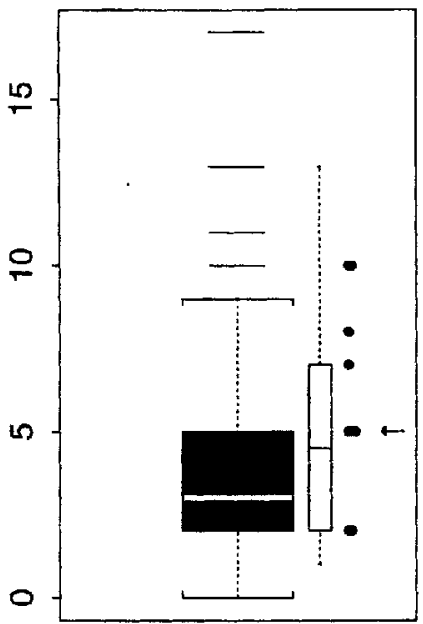

Seashore Errors

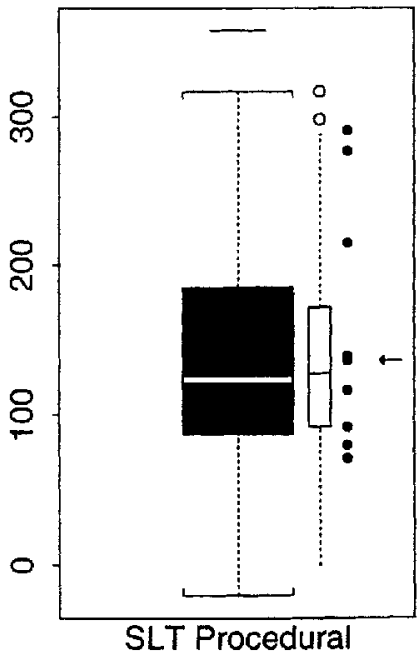

SLT Procedural

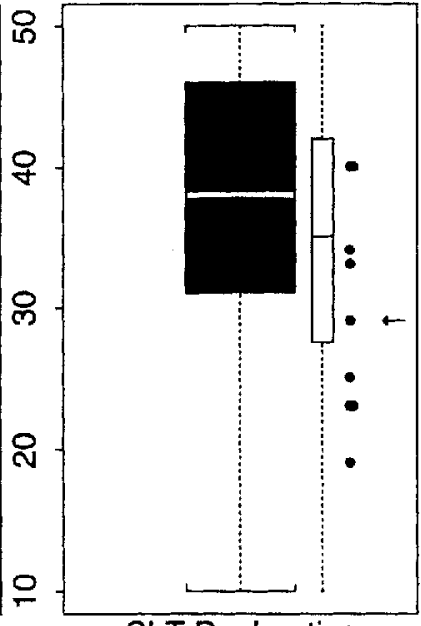

SLT Declarative

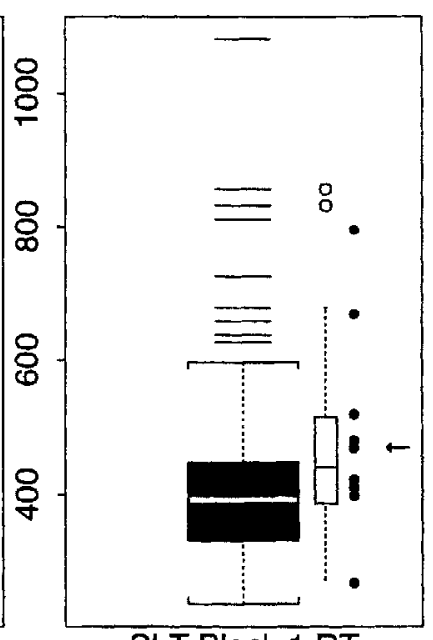

SLT Block 1 RT
Fig. 3. Boxplots comparing WCST performance of FAS patients and the two comparison groups. The left-hand panel compares the groups on the number of categories successfully achieved, with a higher score indicating better performance. The middle panel shows the comparison on the percentage of "other" responses, whereas the right-hand panel compares the groups on the total percentage of errors. Percentages are derived according to the total number of responses, and lower scores indicate better performance on these two variables.
Fig. 4. Boxplots comparing DS subtest and SEASHORE performance of FAS patients and the two comparison groups. The left-hand panel compares groups on the raw score during the "Forward" condition of DS, whereas the middle panel compares groups on the raw score from the "Backward" DS condition; higher scores indicate better performance on DS. The right-hand panel compares groups on the number of SEASHORE errors, with lower scores indicating better performance.
Fig. 5. Boxplots comparing SLT performance of FAS patients and the two comparison groups. On the left is illustrated the "Procedural Score" and in the middle the "Declarative Score;" higher scores on these variables indicate better performance. On the right is shown the reaction time for the first block of trials on the SLT, with a lower score indicating better performance. puzzle pieces for a relatively shorter period of time (perhaps reflecting impulsivity or an unorganized response pattern) $(w=1.79, p=0.073)$. Their performance did not differ from the IQ comparison subgroup who, on average, also had some difficulty with the SVRT. On the SSM, a task requiring memory, motor skill, planning, and visual-spatial processing ability, the FAS patients (on average) took a much longer time than either comparison group to achieve 


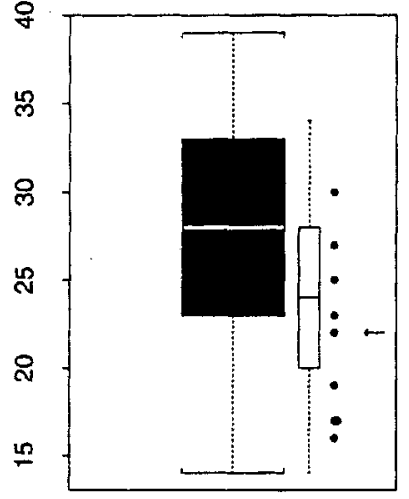

SVRT \# Correct

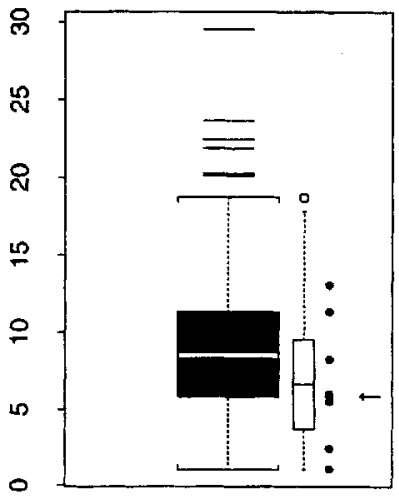

SVRT Study Time
Fig. 6. Boxplots comparing SVRT performance of FAS patients and the two comparison groups. The left-hand panel shows the number of correct responses on the SVRT, and the right-hand panel indicates the median study time required for the subject to decide which response to give. Higher values on these two variables indicate better performance.

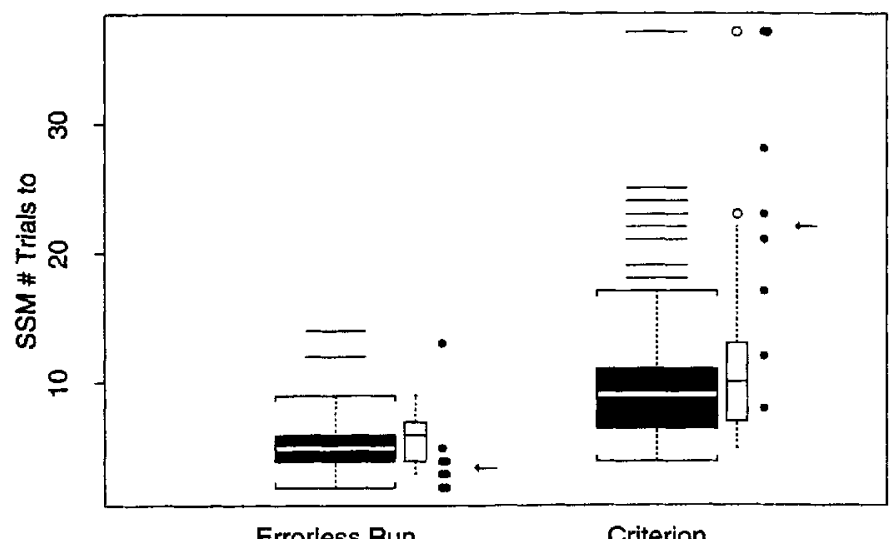

Fig. 7. Boxplots comparing SSM performance between FAS patients and the two comparison groups. Data points for eight FAS patients are shown, because the SSM was only available in pilot version when the first FAS patient was seen. On the left is shown the number of trials needed to reach a criterion of three successive correct runs through the maze, and on the right is displayed the number of trials needed to achieve the first errorless nun through the maze. On both variables, lower scores indicate better performance.

criterion (defined as three consecutive errorless runs), with repeated and perhaps perseverative errors (Cohort comparison group: $w=-3.68, p=0.0002$; IQ comparison subgroup: $w=2.05, p=0.002$ ). Interestingly, 7 of the 8 FAS patients administered the SSM took longer to achieve criterion than, on average, did the IQ comparison subgroup. However, the FAS patients actually required fewer attempts, on average, to accomplish an error-free initial trial when compared with data from either comparison group (Cohort comparison group: $w=2.05, p=0.039$; IQ comparison subgroup: $w=2.55, p=0.010$ ).

\section{Reading Skills}

Two tests were used to tap aspects of reading behavior (Fig. 8). The RSVP task measures one type of reading comprehension and reading speed, whereas the WA subtest assesses phonological processing of nonsense

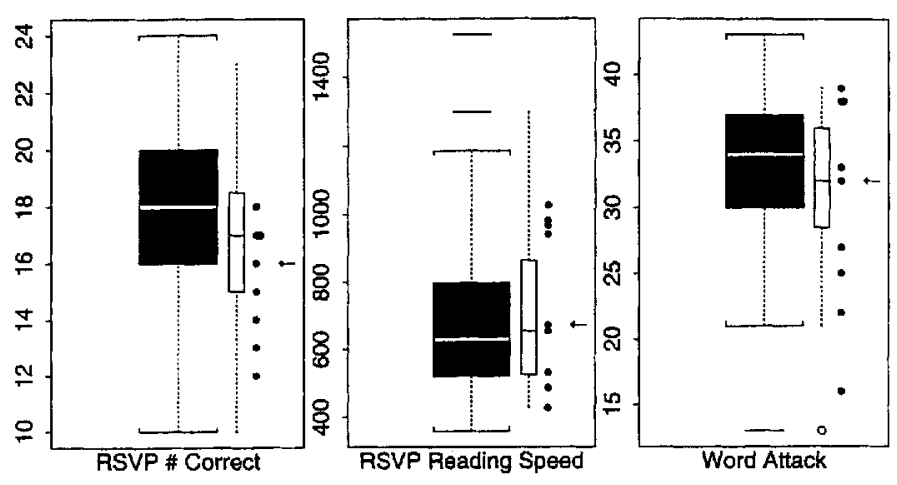

Fig. 8. Boxplots comparing performance of FAS patients and the two comparison groups on the RSVP and WA subtest. The left-hand panel illustrates the number of correct responses to questions on the RSVP, with a higher score indicating better performance. The middle panel presents the median RSVP reading speed in milliseconds (based on all words except the first and last word of each sentence); a lower score indicates faster speed, which does not always mean better performance because accuracy may be reduced. On the right is shown the number of correct responses on WA, with a higher score indicating better performance.

words. On the RSVP task (which requires comprehension of short reading passages), the FAS patients were relatively less accurate than the larger Cohort comparison group $(w=2.25, p=0.023)$, but fairly similar to that of the IQ comparison subgroup. Reading speed in the RSVP task and performance on the WA subtest were similar for FAS patients and both comparison groups.

\section{Profiles of Individual Functioning}

The panels in Figure 9 display four individual FAS patient profiles of neuropsychological scores. These four patients were selected to portray the range of diversity in this patient group. In the profile plots of Fig. 9, the 31 variables are oriented so that higher values indicate poorer performance relative to the larger Cohort comparison group. The dotted line corresponds to the 90th percentile for the Cohort comparison group, so that each point falling above this line indicates that an adolescent FAS patient demonstrated poorer performance on this variable than $90 \%$ of adolescents in the Cohort comparison group. Inspection of these patient profiles shows that no one task was problematic for every patient and that there was clear individual diversity among patients. These profiles also demonstrate that simply knowing the level of a patient's IQ did not always convey the full picture of cognitive deficits among these FAS patients. In the descriptions herein, findings are interpreted roughly from left to right on each of the profiles.

The top panel displays scores from neuropsychological tasks for subject $A$, a female with FAS whose IQ was within normal limits (with no significant verbal-performance split). This patient gave a relatively normative performance on the neuropsychological tests in this battery, illustrated by the fact that very few of her scores fall at or beyond the dotted line. Like one other patient in this clinical sample, this teenaged girl with FAS showed only subtle cognitive decrements and strengths relative to the average perfor- 


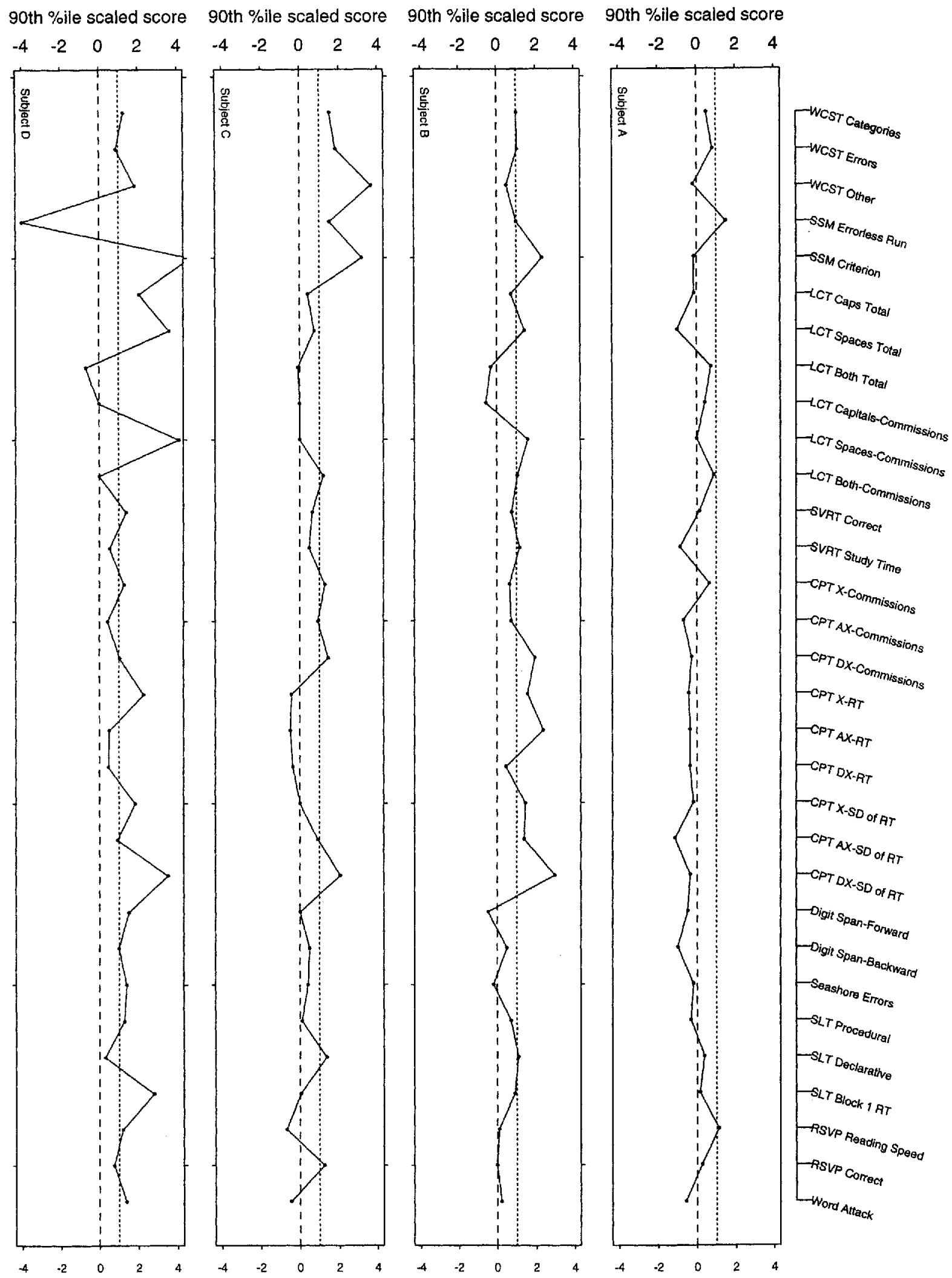

Fig. 9. Four individual patient profiles of the neuropsychological scores. These scores are scaled according to the median and goth percentile of the main Cohort comparison group $(n=174)$. A score of 0 (indicated by a dashed line) corresponds to the Cohort comparison group median, whereas a score of 1 (indicated by a dotted linel corresponds to the 90th percentile of the Cohort comparison group. Before this scaling. selected variables in Fig. 9 were log-transformed in the same way as in preceding figures, but all variables were oriented so that higher values indicate poorer performance relative to the larger Cohort comparison group. To facilitate visualization of study findings, individual scores have been connected in these profile plots. However, because the ordering of the variables is arbitrary, the slopes of these line segments should not be interpreted. 
Tabie 2. Intellectual, Academic Achievement, and Adaptive Behavior Scores for Patients with FAS

\begin{tabular}{|c|c|c|c|}
\hline Task/variables & Mean (SD) & Minimum & Maximum \\
\hline \multicolumn{4}{|l|}{ Wechsler intelligence Scales $(n=9)$} \\
\hline Full-Scale 10 & $91.1(15.9)$ & 70.0 & 118.0 \\
\hline Performance $1 \mathrm{Q}$ & $96.2(17.1)$ & 74.0 & 118.0 \\
\hline Verbal 10 & $87.7(14.8)$ & 67.0 & 114.0 \\
\hline \multicolumn{4}{|c|}{ Wide Range Achievement Test-Revised $(n=8)$} \\
\hline Reading & $98.9(12.4)$ & 87.0 & 127.0 \\
\hline Spelling & $95.9(14.5)$ & 71.0 & 117.0 \\
\hline \multirow[t]{2}{*}{ Arithmetic } & $83.0(12.6)$ & 56.0 & 97.0 \\
\hline & Mean (SD) & Clinical cut-off & No. beyond cut-off \\
\hline Vineland Adaptive Behavior Scale & & & . \\
\hline Adaptive behavior composite & $69.2(22.3)$ & $<70$ & 4 \\
\hline Communication & $73.9(19.8)$ & & \\
\hline Daily living skills & $76.7(19.7)$ & & \\
\hline Socialization & $68.2(25.6)$ & & \\
\hline Maladaptive behaviors (Part 1) & $16.6(9.6)$ & $>10$ & 5 \\
\hline
\end{tabular}

Note: Data are generally reported in scaled scores, which are standardized for a mean of 100 and a standard deviation of 15 for each test. An exception is the VABS maladaptive behaviors score, which is displayed as a raw score.

mance of teenagers her age who did not have significant alcohol exposure in utero. Her difficulties (so few that they are difficult to interpret) can be summarized as slower performance on several complex tasks (see SSM Errorless Run, RSVP Reading Speed). This may actually have been an advantage to her, because slowed speed could enhance her accuracy keeping her performance at the level of her Cohort comparison peers (see SSM Criterion, RSVP Correct).

The second and third panels present scores for two patients with average IQ, no significant verbal-performance split but, compared with agemates, very uneven (yet distinct) performances on this presumably alcohol-sensitive test battery. Subject B, a girl with FAS, had some difficulty with a measure of planning and cognitive flexibility (items from SSM). Her performance reveals problems with several measures of visual-spatial skills (items from LCT Spaces and SVRT), some impulsivity and increased response speed variability during a sustained attention task (items from CPT Commissions and SD of RT), and generally slowed processing speed (items from CPT RT, SLT Block $1 \mathrm{RT}$ ). She also had difficulty with conscious recall of learned information (SLT Declarative). Subject C, a boy with FAS, had even more striking difficulties on measures of planning and cognitive flexibility (items from WCST and SSM), and more marked impulsivity in the sustained visual attention task (items from CPT Commissions). Subject C seemed to have greater problems on the most complex condition of a task (LCT-Both Commissions, CPT DXCommissions) and response speed variability (CPT DX-SD of $\mathrm{RT}$ ). He, too, had problems with conscious recall of learned information (SLT Declarative); but, unlike Subject $\mathrm{B}$, he did not show evidence of slowed processing speed, yet he did have relatively poor reading comprehension (RSVP Correct). In this clinical sample, there were three additional FAS patients with average IQ yet relatively uneven (but individually different) neuropsychological profiles.

The bottom panel presents neuropsychological scores for subject $\mathrm{D}$, a female with borderline IQ (and no significant verbal-performance split). As for all three FAS patients with borderline IQ, for subject D particular deficits were seen on tasks tapping planning and cognitive flexibility (items from WCST and SSM), and on several tasks measuring visual-spatial skills (items from LCT Spaces and SVRT). Subject D also had problems with measures of sustained attention (items from the CPT) on some (but not all) measures of processing speed and efficiency (CPT X-RT, all CPT SD of RT items, SLT block 1 RT, RSVP Reading Speed), and on auditory memory tasks (items from DS and SEASHORE). Unlike most of the FAS patients, however, subject $\mathrm{D}$ also had problems with procedural learning. However, this young woman did show some strengths. She managed an errorless run through the SSM maze much more quickly than, on average, did her Cohort comparison peers. However, her clear difficulty in achieving criterion on the SSM indicates that she was unable to learn from her initial maze experience and repeat her success on three consecutive trials, as did her peers with little or no prenatal alcohol exposure. Subject D was able to accurately cross out capital letters during a complex focused attention task (LCT Both Total, LCT Both Commissions) and show conscious recall of learned information (SLT Declarative), performing at almost the same level as teens her age without heavy alcohol exposure. Overall, each of the three patients with borderline IQ had problems with somewhat different aspects of tasks tapping the skills described for subject $D$. These FAS patients generally showed some degree of impairment across much of the test battery.

\section{Intellectual Status, Academic Achievement, and Adaptive Behavior}

Table 2 presents IQ, academic achievement, and adaptive behavior scores for the FAS patient group. The group mean Full-Scale IQ for the nine patients with FAS was within the average range, with three patients in the borderline range and six patients in the low to high average IQ range. ${ }^{31}$ Consistent with prior literature, Performance IQ scores were relatively 
Table 3. Behavior Problems and Social Competence Scores for the Cohort Comparison Group $(n=145)$, IQ Comparison Subgroup ( $n=40$ ), and FAS

Patients $(n=9)$

\begin{tabular}{|c|c|c|c|c|c|c|c|}
\hline & \multicolumn{2}{|c|}{ Cohort comparison group } & \multicolumn{2}{|c|}{ IQ comparison subgroup } & \multicolumn{2}{|c|}{ FAS patients } & \multirow[b]{2}{*}{ Clinical cut-off } \\
\hline & Boys & Girls & Boys & Giris & Boys & Girls & \\
\hline Behavior problems & $50.4(12.5)$ & $50.0(12.5)$ & $55.6(13.1)$ & $57.8(7.5)$ & $72.7(13.7)$ & $61.2(15.5)$ & $>63$ \\
\hline Social competence & $48.2(9.5)$ & $50.7(9.7)$ & $45.4(9.6)$ & $42.7(7.3)$ & $31.3(7.4)$ & $40.5(12.5)$ & $<37$ \\
\hline
\end{tabular}

Note: These total behavior problems and total social competence scales come from the CBCL/4-18. CBCL/4-18 values are T-scores, which are standard scores

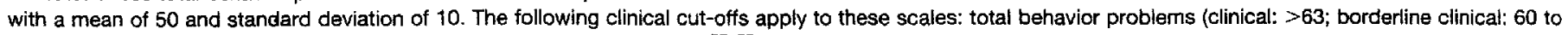
63) and total social competence (clinical: <37; borderline clinicai: $37-40$ ). ${ }^{57-59}$

higher than Verbal IQ scores, although there was not a marked Verbal-Performance gap for all subjects. Academic achievement on the WRAT-R was generally consonant with IQ, except for relatively lower arithmetic achievement scores. As can be seen in Table 2, adaptive behavior was clearly problematic for these teens with FAS. On the VABS, results showed poorer performance than expected based on tested IQ, with an average Adaptive Behavior Composite score that falls below the clinical cut-off and indicates significantly delayed adaptive function. Performance was relatively worse in the Socialization Domain, compared with the domains of Communication and Daily Living Skills.

\section{Behavior Problems and Social Competence}

Table 3 displays caregiver report of behavior problems and social competence, as assessed via mean scores and clinical cut-offs from the CBCL/4-18. On average, total behavior problem T-scores are well within normal limits for both boys and girls in the Cohort comparison group and IQ comparison subgroup. However, the mean score for the female FAS patients (mean $=61.2$ ), which falls in the borderline clinical range, appears higher than those of the comparison groups. Male patients with FAS have an average total behavior problems score (mean $=72.7$ ) that falls well beyond both comparison groups and above the clinical cut-off for the test (Tscore $>63$ ). On an individual basis, 2 of the 3 boys with FAS and 3 of the 6 girls with FAS had total behavior problems scores that fell clearly in the clinical range. Many types of problems were reported, with attention, social, and thought problems (odd behaviors) often part of the behavioral picture-but, for individual patients, there were also reports of withdrawn behavior, and of aggression combined with somatic problems, anxious/depressed, or withdrawn behavior. These data are congruent with the significant level of maladaptive behavior revealed by the VABS, shown in Table 2, on which five of the eight FAS patients assessed with this tool scored well above the clinical cut-off.

Social competence scores, as shown in Table 3 , reveal a similar pattern. On average, male and female FAS patients received caregiver ratings indicating poorer social competence than did the Cohort comparison group or IQ comparison subgroup. Boys with FAS were rated as having poorer social competence than were girls with FAS. On an individual basis, 2 of the 3 boys and 2 of the 6 girls had total social competence levels that fell below the clinical cut-off. (In addition, the remaining boy with FAS and two more girls with FAS were rated below the borderline clinical cut-off in social competence.) Subscale analysis indicated that ratings of participation in activities were within normal limits for all patients, and adequate quality of family/peer relationships was reported for six of the teenagers with FAS. However, six of these adolescent FAS patients showed poor school competence, with scores within the borderline clinical or clinical range. Only two of the nine FAS patients (one with borderline and one with average IQ) were viewed by their caregivers as clearly free of behavior problems and possessing adequate social competence (across all domains, including school).

\section{DISCUSSION}

Adolescents with FAS displayed a variety of cognitive deficits when tested with a broad range of attention, memory, and reading tasks, even though these patients were not considered mentally retarded and the majority had average reading scores on the WRAT-R achievement test. As in other studies of FAS patients, ${ }^{23,26}$ there was marked individual diversity in the patients' profiles of cognitive skills, with some patients displaying marked cognitive difficulties on an alcohol-sensitive battery even though their tested IQ was within normal limits. There was no "gold standard" test on which every patient with FAS did poorly. However, instruments were identified that may be clinically useful for detecting alcohol-related cognitive deficits during adolescence.

\section{Patterns of Cognitive Performance}

In this exploratory study, impairment in visual-spatial skills commonly occurred among these teenagers with FAS. They even performed more poorly on some tasks than did peers with equivalent IQ, but little or no prenatal alcohol exposure. Most clearly, this included poorer performance on the "Spaces" condition of the LCT (a focused attention task requiring perception of spatial information) and the SSM (a test of spatial memory). These findings fit with extensive animal research documenting alcohol-related spatial deficits, ${ }^{60}$ with careful study by Uecker and Nadel ${ }^{19}$ of visuospatial deficits and impairment in object and spatial memory (in children with FAS ranging from age 5 to 14 ), and with discussion by Mattson et al. ${ }^{61}$ of the association of spatial and other behavioral deficits with neuroimaging evidence of alcohol-related brain damage. Study results 
also revealed a trend toward subtle deficits within the FAS group on one measure of short-term auditory attention and memory, the "Backwards" condition of the DS-B subtest, even when compared with the performance of an IQ comparison group of peers. These findings support the results of Kodittuwakku et al., ${ }^{24}$ indicating diminished auditory attentional capacity among school-aged FAS/FAE subjects.

Problems with cognitive flexibility and planning are consistent clinical observations in research on FAS. Indeed, on two tasks tapping these executive function skills (and working memory), the teen-aged FAS patients in this sample typically took a very long time to achieve criterion and showed apparent disorganization and perseveration, performing more poorly than did the IQ comparison subgroup. On the WCST, the FAS patients showed a relatively large percentage of errors when responding, including disorganized "other" responses. On the SSM, the teen-aged FAS patients often repeated the same error many times, seemingly unable to "hold" the correct solution in mind and reproduce it reliably on three consecutive trials, or to efficiently make use of the computer's feedback to improve their performance. These findings are consistent with the elevated rates of perseveration and intrusion errors noted in the neuropsychological studies of fetal alcohol-affected individuals conducted by Kerns et al. $^{23}$ and Mattson et al., ${ }^{21,27,29}$ and the problems in planning a route through a maze seen among children with FAS by Uecker and Nadel. ${ }^{19}$ Along with clear impairment on two tests thought to require encoding and retrieval from working memory, the SVRT and the DS-B (also thought to tap executive functioning), these findings are also congruent with Kodituwakku et al.' ${ }^{24}$ interpretation that the capacity to guide behavior by mental representation is a primary cognitive mechanism selectively impaired in individuals with FAE. Overall, the present findings also fit very well with a conceptual framework on FAS articulated by Mattson and Riley. These researchers have reported volumetric reductions (and dysgenesis) in the basal ganglia of patients with FAS, and pointed out that this group of CNS structures is associated with spatial memory, goal-directed behavior (i.e., planning), and the ability to switch behavioral sets (which, if impaired, might manifest as an increase in perseverations). ${ }^{22,61}$

Recent study of FAS patients ${ }^{20,27}$ is beginning to identify aspects of memory selectively damaged or left untouched by in utero exposure to alcohol. In the current study, FAS patient performance on a measure of procedural memory (i.e., knowing "how," memory dependent on prior experience) generally appeared intact. (At this time, we do not have the data to assess the possibility that different baseline reaction times of the FAS patients and comparison subjects may obscure actual group differences.) In contrast, patients typically performed poorly relative to their Cohort comparison peers on a declarative memory task (i.e., knowing "what," memory requiring conscious remembrance of a prior episode). Because the performance of the FAS pa- tients differed only from the Cohort comparison group and not the IQ comparison subgroup, the declarative memory deficit observed herein may arise from multiple causes, including alcohol exposure. This pattern of performance on procedural and declarative memory tasks is similar to that seen in recent epidemiological study of alcohol effects ${ }^{34}$ and in brain-injured patient groups, such as those with Korsakoff's syndrome, Alzheimer's, or other memorydisordered groups. ${ }^{62-64}$

Difficulties in processing speed and accuracy seen among the FAS patients in this small sample study fit well with other data from clinical research on this population. ${ }^{5,16,17}$ Because the IQ comparison subgroup was also observed to have problems with processing speech and accuracy, such deficits may represent a final common pathway for CNS dysfunction arising from a variety of causes, including prenatal alcohol exposure. On the CPT, the FAS group tended toward greater intraindividual response speed variability than cohort comparison subjects, which may stem from alcohol-related microlapses in attention, as previously suggested by Streissguth et al. ${ }^{37}$ The FAS patients had slower response times on block 1 of the relatively easy SLT memory task; yet, on the more complex SVRT, they often acted more quickly than comparison subjects with what appeared to be a corresponding increase in rate of error. This is notable because an optimal balance between speed and accuracy appears central to many human mental abilities and is certainly, essential on many cognitive tests. ${ }^{34}$

There is a close, but not complete, correspondence between the current clinical findings and results of the epidemiological Seattle Longitudinal Study of Alcohol and Pregnancy (the "Cohort Study"), in which the impact of lower dose "social drinking" was examined. As expected because alcohol is a teratogen, the cognitive deficits of the heavily alcohol-exposed FAS patients were often quite similar in type (but greater in magnitude) to the dose-response pattern of alcohol-related impairment observed using the same neuropsychological battery in the Cohort Study during early adolescence. The Cohort Study revealed memory and attention deficits related to lower levels of alcohol exposure on the LCT, DS, SSM, ${ }^{37}$ and SVRT. ${ }^{34}$ The measure of procedural memory from the SLT was not highly associated with alcohol exposure in either the Cohort Study $^{34}$ or the present data. However, in the Cohort Study, subtle alcohol-related deficits in attention and phonological processing were revealed via performance on the CPT and WA tests, ${ }^{36,37}$ yet these measures were less sensitive in this clinical study of patients with FAS. The discrepancy on WA may be due to possible reliability problems with subjective aspects of scoring the WA responses. In this clinical study, examiners may have accepted slightly imperfect WA performance from the patient group relative to the level expected of the population-based Cohort Study subjects. On the other hand, the discrepancy between the two studies on these tasks may be due to the wide individual variability among the FAS patients (with often an approximately bi- 
modal distribution and thus limitations on what a small sample study can detect); this suggests the need for replication using a larger group of alcohol-affected subjects, which is presently underway. In another discrepant finding, performance on the computerized WCST in the epidemiological Cohort Study was not strongly associated with lower levels of prenatal alcohol exposure during early adolescence, ${ }^{37}$ yet WCST scores were extraordinarily low among these heavily alcohol-exposed teen-aged FAS patients. Perhaps the WCST taps what Mattson and colleagues ${ }^{61}$ describe as underlying deficiencies related to the frontal regions of the brain that may occur among individuals with FAS, but are not as clear among those who are less heavily exposed.

\section{Pattems of Performance in Adaptive Behavior}

Overall, this group of FAS patients was rated as having significant problems in adaptive behavior (especially in the socialization domain). Over half of this group showed clinically elevated levels of a spectrum of behavior problems, and competence in school was an especially serious concern. These findings fit with recent clinical research suggesting that many individuals with FAS have problems in adaptive behavior and "secondary disabilities" (such as mental health, school, or job problems) that go beyond their primary CNS dysfunction. ${ }^{5,9,11-13,65,66}$ The high rate of problem behaviors among these teenagers with FAS is also congruent with a dose-response association established in the Cohort Study between increased prenatal alcohol exposure and a greater degree of behavior problems in early adolescence (measured through adolescent and parent interview, self-report questionnaires for both teen and parent, and ratings by research examiners blinded to the subjects' exposure history and earlier assessments). ${ }^{33}$ Of course, the rearing history of the FAS patients, with a variable degree of family instability and environmental trauma, partly explains emergence of these secondary disabilities, just as the environmental experiences of the stable, middle class Cohort Study participants also show some association with behavioral outcome ${ }^{33}$ But cognitive (and linguistic) deficits found among these FAS patients-especially if such deficits are not identified or are misunderstood-may also contribute to their lack of success in many work and school experiences, and their general failure in daily function.

\section{Future Research Directions}

This small sample, exploratory study was intended to generate research questions for the field of FAS, and the findings require replication. Programmatic, theory-driven neuropsychological research can more fully describe the serious clinical disorder of FAS and wider range of alcoholrelated conditions, and illuminate the status of underlying brain systems. Needed are larger sample sizes, comparisons of deficits seen in FAS versus those seen in other develop- mental disabilities, individual profiling, and systematic testing paired with imaging studies of brain structure and function. Skills at the intersection of language, thought, and social competence should be examined, such as mental state reasoning, verbal self-regulation, narrative production, and other aspects of social-communicative competence ${ }^{67}$ Also needed is component analysis of assessment results to identify primary cognitive mechanisms involved in alcohol effects, ${ }^{25}$ and to further search for alcohol effects using constructs such as speed-accuracy tradeoffs, ${ }^{34}$ performance variability, and temporal and other error patterns (P.D. Connor and colleagues, unpublished data). In addition, "dynamic assessment," which probes for contexts within which patients are able to improve their behavior, ${ }^{68}$ and careful study of exposed individuals who are resilient to alcohol effects, could be fruitful. Such research, and the development of clinically useful test batteries, can lay the groundwork for creating more effective intervention strategies, and perhaps alter the definitions of traditional school or mental health categories of impairment so that patients with FAS can receive needed services.

\section{ACKNOWLEDGMENTS}

We sincerely acknowledge the assistance of Richard Gonzalez, Ph.D., in suggesting strategies for data analysis and interpretation, and the assistance of Beth Kerr, Ph.D., in reviewing portions of this manuscript.

\section{REFERENCES}

1. Lemoine P, Harousseau $\mathbf{H}$, Borteyru JP, Menuet JC: Children of alcoholic parents: Abnormalities observed in 127 cases. Selected Translations of International Alcoholism Research. STIAR \#1. Rockville, MD, National Clearinghouse for Alcohol Information, 1968

2. Jones KL, Smith DW, Ulleland CN, Streissguth AP: Pattern of malformation in offspring of chronic alcoholic mothers. Lancet 1:12671271,1973

3. Clarren SK, Smith DW: The fetal alcohol syndrome. N Engl J Med 298:1063-1067, 1978

4. Streissguth AP, Clarren SK, Jones KL: Natural history of the fetal alcohol syndrome: A ten-year follow-up of eleven patients. Lancet 2:8591,1985

5. Streissguth AP, Aase JM, Clarren SK, LaDue RA, Randels SP, Smith DF: Fetal alcohol syndrome in adolescents and adults. JAMA 265:1961-1967, 1991

6. Lemoine P, Lemoine P: Avenir des enfants de mères alcooliques (Étude de 105 cas retrouvés à l'âge adulte) et quelques constatations d'intérêt prophylactique. ["Outcome in the offspring of alcoholic mothers (study of one hundred and five adults) and considerations with a view to prophylaxis"]. Ann Pediatr 39:226-235, 1992

7. Majewski F: Alcohol embryopathy: Experience in 200 patients. Dev Brain Dys 6:248-265, 1993

8. Spohr HL, Willms J, Steinhausen HC: Prenatal alcohol exposure and long-term developmental consequences. Lancet 341:907-910, 1993

9. Steinhausen HC, Willms J, Spohr HL: Long-term psychopathological and cognitive outcome of children with fetal alcohol syndrome. J Am Acad Child Adolesc Psychiatry 32:990-994, 1993

10. Steinhausen HC, Willms J, Spohr HL: Correlates of psychopathology and intelligence in children with fetal alcohol syndrome. $J$ Am Acad Child Adolesc Psychiatry 35:323-331, 1994 
11. Streissguth AP, Barr HM, Kogan J, Bookstein FL: Understanding the occurrence of secondary disabilities in clients with fetal alcohol syndrome and fetal alcohol effects. Seattle, WA, University of Washington Publication Services, 1996

12. Streissguth AP, Barr HM, Kogan J, Bookstein FL: Primary and secondary disabilities in fetal alcohol syndrome, in Streissguth AP, Kanter J (eds): The Challenge of Fetal Alcohol Syndrome: Overcoming Secondary Disabilities. Seattle, WA, University of Washington Press, 1997, pp 25-39

13. Steinhausen HC, Spohr HL: Long-term outcome of children with fetal alcohol syndrome: Psychopathology, behavior, and intelligence. Alcohol Clin Exp Res 22:334-338, 1998

14. West JR, Goodlett CR, Brandt CP: New approaches to research on the long-term consequences of prenatal exposure to alcohol. Alcohol Clin Exp Res 14:684-689, 1990

15. Steinhausen HC, Nestler V, Spohr HL: Development and psychopathology of children with the fetal alcohol syndrome. I Dev Behav Pediatr 3:49-54, 1982

16. Conry J: Neuropsychological deficits in fetal alcohol syndrome and fetal alcohol effects. Alcohol Clin Exp Res 14:650-655, 1990

17. Nanson JL, Hiscock $\mathbf{M}$ : Attention deficits in children exposed to alcohol prenatally. Alcohol Clin Exp Res 14:656-661, 1990

18. Janzen LA, Nanson JL, Block GW: Neuropsychological evaluation of preschoolers with fetal alcohol syndrome. Neurotoxicol Teratol 17:273279, 1995

19. Uecker A, Nadel L: Spatial locations gone awry: Object and spatial memory deficits in children with fetal alcohol syndrome. Neuropsychologia 34:209-223, 1996

20. Coles CD, Platzman KA, Raskind-Hood CL, Brown RT, Falek A, Smith IE: A comparison of children affected by prenatal alcohol exposure and attention deficit, hyperactivity disorder. Alcohol Clin Exp Res 21: $150-161,1997$

21. Mattson SN, Riley EP, Jernigan CLE, Ehlers CL, Delis DC, Jones KL, Stern C, Johnson KA, Hesselink JR, Bellugi U: Fetal alcohol syndrome: A case report of neuropsychological, MRI and EEG assessment of two children. Alcohol Clin Exp Res 16:1001-1003, 1992

22. Mattson SN, Riley EP, Jernigan TL, Garcia A, Kanenko WM, Ehlers CL, Jones KL: A decrease in the size of the basal ganglia following prenatal alcohol exposure: A preliminary report. Neurotoxicol Teratol 16:283-289, 1994

23. Kerns KA, Don A, Mateer CA, Streissguth AP: Cognitive deficits in nonretarded adults with fetal alcohol syndrome. $J$ Learn Dis 30:685-693, 1997

24. Kodituwakku PW, Handmaker NS, Cutlęr SK, Weathersby EK, Handmaker SD: Specific impairments in self-regulation in children exposed to alcohol prenatally. Alcohol Clin Exp Res 19:1558-1564, 1995

25. Kodituwakku PW, Handmaker NS, Cutler SK, Weathersby EK, Handmaker SD, Aase JM: Impaired goal management in working memory in FAS/FAE. Paper presented at the Research Society on Alcoholism, San Antonio, TX, 1995

26. Kopera-Frye K, DeHaene S, Streissguth AP: Impairments of number processing induced by prenatal alcohol exposure. Neuropsychologia 34:1187-1196, 1996

27. Mattson SN, Riley EP, Delis DC, Stern C, Lyons-Jones K: Verbal learning and memory in children with fetal alcohol syndrome. Alcohol Clin Exp Res 20:810-816, 1996

28. Mattson SN, Gramling L, Delis DC, Jones KL, Riley EP: Globallocal processing in children prenatally exposed to alcohol. Child Neuropsychol 2:165-175, 1996

29. Mattson SN, Riley EP, Gramling L, Delis DC, Jones KL: Neuropsychological comparison of alcohol-exposed children with or without physical features of the fetal alcohol syndrome. Neuropsychology 12:146153, 1998

30. Mattson SN, Riley EP: A review of the neurobehavioral deficits in children with fetal alcohol syndrome or prenatal exposure to alcohol. Alcohol Clin Exp Res 22:279-294, 1998
31. Wechsler D: The Wechsler Intelligence Scale for Children, revised. New York, The Psychological Corporation, 1974

32. Streissguth AP, Bookstein FL, Sampson PD, Barr HM: The Enduring Effects of Prenatal Exposure on Child Development: Birth through 7 Years, A Partial Least Squares Solution. Ann Arbor, MI, University of Michigan Press, 1993

33. Carmichael Olson H, Streissguth AP, Sampson PD, Barr HM, Bookstein FL, Thiede K: Association of prenatal alcohol exposure with behavioral and learning problems in early adolescence. J Am Acad Child Adolesc Psychiatry 36:1187-1194, 1997

34. Sampson PD, Kerr B, Carmichael Olson H, Streissguth AP, Bookstein FL, Hunt E, Barr HM, Thiede K: The effects of prenatal alcohol exposure on adolescent cognitive processing: A speed-accuracy tradeoff. Intelligence 24:329-353, 1997

35. Streissguth AP, Bookstein FL, Sampson PD, Barr HM: Attention: Prenatal alcohol and continuities of vigilance and attentional problems from 4 through 14 years. Dev Psychopathol 7:419-446, 1995

36. Streissguth AP, Barr HM, Carmichael Olson H, Sampson PD, Bookstein FL, Burgess DM: Drinking during pregnancy decreases word attack and arithmetic scores on standardized tests: Adolescent data from a population-based prospective study. Alcohol Clin Exp Res 18:248-254, 1994

37. Streissguth AP, Sampson PD, Carmichael Olson H, Bookstein FL, Barr HM, Scott M, Feldman J, Mirsky AF: Maternal drinking during pregnancy: Attention and short-term memory in 14-year-old offspring: A longitudinal prospective study. Alcohol Clin Exp Res 18:202-218, 1994

38. Rosvold HE, Mirsky AF, Sarason I, Bransome ED, Beck LN: A continuous performance test of brain damage. J Consult Psychiatry 20: $343-350,1956$

39. Mirsky AF, Anthony BJ, Duncan CC, Ahearn MB, Kellam SG: Analysis of the elements of attention: A neuropsychological approach. Neuropsychol Rev 2:109-145, 1991

40. Talland GA: Deranged Memory. New York, Academic Press, 1965

41. Heaton RK: A Manual for the Wisconsin Card Sorting Test. Odessa, FL, Psychological Assessment Resources, 1981

42. Lezak MD: Neuropsychological Assessment, ed 3. New York, Oxford University Press, 1995

43. Shimamura AP, Janowsky JS, Squire LR: What is the role of frontal lobe damage in memory disorders?, in Levin HS, Eisenberg HM, Benton AL (eds): Frontal Lobe Function and Dysfunction. Oxford, Oxford University Press, 1991

44. Seashore CB, Lewis C, Saltveit JG: Seashore Measures of Musical Talent: Manual. New York, Psychological Corporation, 1960

45. Squire L: Mechanisms of memory. Science 232:1612-1619, 1986

46. Nissen MJ, Bullemer P: Attentional requirements of learning: Evidence from performance measures. Cogn Psychol 19:1-32, 1987

47. Feldman J, Kerr B, Streissguth AP: Correlational analyses of procedural and declarative learning performance. Intelligence 20:87-114, 1995

48. Hunt E, Pellegrino JW, Frick RW, Farr SA, Alderton D: The ability to reason about movement in the visual field. Intelligence 12:77-100, 1988

49. Milner B: Visually-guided maze learning in man: Effects of bilateral hippocampal, bilateral frontal and unilateral cerebral lesions. Neuropsychologia 3:317-338, 1965

50. Milner B: Visual recognition and recall after right temporal lobe excision in man. Neuropsychologia 6:191-209, 1968

51. Kintsch W, VanDijk TA: Towards a model of text comprehension and production. Psychol Rev 85:363-394, 1978

52. Woodcock RW: Woodcock Reading Mastery Tests-Revised. Circle Pines, MN, American Guidance Service, 1987

53. Siegel LS: IQ and leaming disabilities: R.I.P., in Swanson HL, Keogh B (eds): Learning Disabilities: Theoretical and Research Issues. Hillsdale, NJ, Lawrence Eribaum \& Associates, 1990

54. Siegel LS, Heaven RK: Categorization of learning disabilities, in Ceci SJ (ed): Handbook of Cognitive, Social, and Neuropsychological 
Aspects of Learning Disabilities, vol 1, chap 4. Hillsdale, NJ, Lawrence Erlbaum \& Associates, 1986, pp 95-122

55. Jastak S, Wilkinson GS: Manual for the Wide Range Achievement Test-Revised. Wilmington, DE, Jastak Associates, 1984

56. Sparrow SS, Balla DA, Cicchetti DV: Vineland Adaptive Behavior Scales: Interview Edition Survey Form Manual. Circle Pines, MN, American Guidance Service, 1984

57. Achenbach TM, Edelbrock G: Manual for the Behavior Checklist and Revised Child Behavior Profile. Burlington, VT, University of Vermont, Department of Psychiatry, 1983

58. Achenbach TM: Integrative guide for the $1991 \mathrm{CBCL} / 4-18$, YSR, and TRF profiles. Burlington, VT, University of Vermont, Department of Psychiatry, 1991

59. Achenbach TM: Scoring Program for the CBCL/4-18. Burlington, VT, University of Vermont, Department of Psychiatry, 1993

60. Goodlett CR, Bonthius DJ, Wasserman EA, West JR: An animal model of CNS dysfunction associated with fetal alcohol exposure: Behavioral and neuroanatomical correlates, in Gormezano I, Wasserman EA (eds): Learning and Memory: The Behavioral and Biological Substrates. Hillsdale, NJ, Lawrence Erlbaum \& Associates, 1992, pp 183-208

61. Mattson SN, Jemigan TL, Riley EP: MRI and prenatal alcohol exposure: Images provide insight into FAS. Alcohol Health Res World $18: 49-52,1994$

62. Corkin S: Acquisition of motor skill after bilateral medial temporal lobe excision. Neuropsychologia 6:255-265, 1968

63. Nissen MJ, Willingham D, Hartman M: Explicit and implicit remembering: When is learning preserved in amnesia? Neuropsychologia 27:341-352, 1989

64. Knopman DS, Nissen MJ: Implicit learning in patients with probable Alzheimer's disease. Neurology 37:784-788, 1987

65. Streissguth AP: A long-term perspective of FAS. Alcohol Health Res World 18:74-81, 1994

66. Thomas SE, Kelly SJ, Mattson SN, Riley EP: Comparison of social abilities of children with fetal alcohol syndrome to those of children with similar IQ scores and normal controls. Alcohol Clin Exp Res 22:528-533, 1998

67. Coggins TE, Friet T, Morgan T: Analyzing narrative productions in older school-age children and adolescents with fetal alcohol syndrome: An experimental tool for clinical applications. Clin Ling Phonet 12:221-236, 1997

68. Rourke BP: Syndrome of Nonverbal Learning Disabilities: Neurodevelopmental Manifestations. New York, Guilford Press, 1995 